\title{
Crossing disciplinary boundaries: Students' experiences of facilitating a learning support programme at a South African university
}

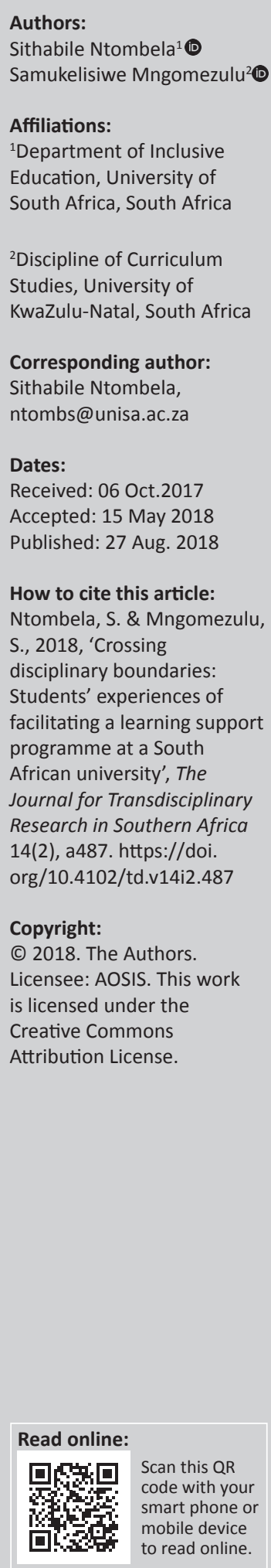

Authors:

Affiliations:

${ }^{1}$ Department of Inclusive Education, University of

${ }^{2}$ Discipline of Curriculum

Studies, University of

Corresponding author:

Sithabile Ntombela,

Dates:

Accepted: 15 May 2018

How to cite this article:

Ntombela, S. \& Mngomezulu,

S., 2018, 'Crossing

disciplinary boundaries:

Students' experiences of

programme at a South

African university', The

Journal for Transdisciplinary

14(2), a487. https://doi.

org/10.4102/td.v14i2.487

Copyright:

C 2018. The Authors.

Licensee: AOSIS. This work

is licensed under the

Creative Commons

Attribution License.

mobile device
Increased access to higher education has brought into focus the under-preparedness of students for higher education and vice versa. As such, various programmes have been developed to enhance students' success in universities. In one institution, an administrator and a lecturer collaborated with senior university students to facilitate a learning support programme where the students acted as peer mentors. The study sought to document students' experiences of facilitating a peer-mentorship programme that targets first year students as well as senior students who were regarded as at risk of academic exclusion. Using a qualitative case study and Bandura's social learning theory, 30 peer mentors were purposively selected to generate data through a peer mentors' reflection workshop. Findings of the study suggest that the mentors were more successful in working with first year students than with senior students. The article concludes that, because of the training provided, mentors were knowledgeable about the programme and the resources available to support mentees. Further studies should solicit mentees' views and experiences of such a programme, especially those reluctant to take part, as that will highlight areas that require attention to raise the participation and academic success of all participants.

\section{Introduction}

The 21st century has brought about an increased demand for access into higher education (HE) on the African continent as more people recognise the role HE plays in modernisation and development (Teferra \& Altbach 2004:21). This increased demand for access into HE is said to be a result of massification (Akoojee \& Nkomo 2007:385), a process brought about by pressure to transform universities from being elitist to making access possible to those who were previously excluded (Altbach 1999). In South Africa, black people, despite being in the majority, were previously marginalised and were largely excluded from HE during the days of apartheid.

Of course the apartheid regime did create a limited number of black universities as part and parcel of its unfair separation of the races. Institutions designated as black universities were far less resourced than white universities. The scars of this unfair treatment of universities remain to this day; thus, there is reference to previously disadvantaged institutions of HE. The demise of apartheid was accompanied by the call for transformation across all sectors of society, and HE has not been left untouched by the winds of transformation. It is against this background that the passing of Education White Paper 3: A Programme for Higher Education Transformation (Department of Education 1997) called for radical transformation of how higher education institutions (HEIs) respond to social needs.

This call saw an unprecedented increase in the admission of, and funding for, previously marginalised students. At the same time, worldwide, 21st century economies have become 'increasingly complex and technologically-based', thus placing a huge demand for skills taught through university study (Altbach 1999:108). As a result, there has been a surge in the rates of students from different schooling backgrounds accessing HE. Post-apartheid South Africa has also witnessed a huge demand for university access by black students, many of whom are products of poorly resourced schools. In addition, some of the students come from economically disadvantaged backgrounds.

This process has brought into focus the question of preparedness and readiness for the HE sector. Because student retention is highly dependent on their success in their studies, HEIs have had to consider and implement strategies that facilitate student success. It is important to mention that 
students who are less prepared for $\mathrm{HE}$ are an unpalatable reality that cannot be swept under the carpet in the post-apartheid era. However, what is more important is to ask: Are HEIs prepared for students who are underprepared for university study? It is against this background that universities across post-apartheid South Africa are vigorously engaged in a range of interventions whose common denominator is assisting underprepared students or disadvantaged students. Once underprepared students have accessed HE (physical entry), there is a critical need to ensure that such students gain epistemological access and are enabled to achieve academic success.

This article is about a peer mentoring programme offering tailored support via smaller, peer-led sessions held weekly. It is an intervention programme developed to support first year students transitioning from school to university and senior students who are identified by the system as 'at risk' of academic exclusion. It is a cross level peer tutoring programme where the 'targeted' students are supported by third to fourth year undergraduate as well as post-graduate students with good academic records.

We worked together in our capacity as lecturer (lecturer in Psychology and Inclusive Education) and administrator (student support) with the sole purpose to provide academic support to students on this campus using peer mentors. At the beginning of each academic year, we invite new students to be part of the peer-mentorship programme and we post information on notice boards to ensure that they are aware of the programme and its importance. We also counsel those who are at risk of academic exclusion and encourage them to enlist on this programme. Attendance is not compulsory but those at risk of failure are aware that regular attendance will help them get back on track academically. The mentors, most of whom have served as orientation week mentors, are trained to equip them with the necessary skills to facilitate the formal and informal mentorship sessions.

The formal programme runs every week until the week before examinations start. Every week on Thursday there is a planned programme for one period (45 min) during the timetabled free period. This programme is available to all those enlisted on the peer-mentorship programme. However, because it is also advertised in strategic places within the university, the Thursday programme is open to anyone. Then there is a follow-up programme where mentors schedule individual and group meetings with their mentees with the intention to reinforce whatever was taught on Thursday. There is also an informal programme facilitated through the drop-in centre where mentors are on duty (there is a roster) to provide support to those who drop-in at any time. This is also the meeting venue available to mentors and mentees during office hours. Mentors' timetables and their contact details are on display in this room to enable mentees to book appointments at convenient times when they and their mentors are free. Should there be a need to refer a mentee to a subject specialist or another unit for additional support, the mentors make the necessary arrangements.
The call for papers, to which we responded, asked authors to situate their articles within the transdisciplinary tradition. We have, therefore, provided a brief overview of transdisciplinarity and attempted to show its links to the current article. We believe that the study of peer mentoring offers a fertile ground on which the transdisciplinary tradition can stand. We live in a world in which compartmentalisation of disciplines or knowledge is not helpful. For example, in which discipline can we say we can firmly situate peer mentoring? It is impossible to choose one discipline or branch of knowledge that can take full monopoly to address peer mentoring. Transdisciplinarity confirms unity of knowledge. It is a research effort that addresses issues that cross disciplinary boundaries, and we believe peer mentoring is one such issue that crosses disciplinary boundaries (Nicolescu 2008).

In the next section, we provide a literature review followed by a description of the nature of peer mentoring that takes place at the HEI that is under study. This section is followed by our discussion of the methodology of the study, then we provide the results and discussion of the results. In the last section of the article, we provide a summary, conclusion and recommendations for further research.

\section{Mentorship as a form of student support in South African higher education institutions: An overview of the literature}

The objective of the study whose findings are discussed in the current article was to document the experiences of mentors in facilitating this programme. The critical question that the study sought to answer was: What are mentors' experiences of running this peer-mentorship programme? The study was informed by the social learning theory of Bandura (1977). The most important aspect of the social learning theory is the collaborative nature of the learning process. This is key in peer mentoring where the mentor and the mentee are expected to work together and hopefully, learn together. Mentoring is not a passive process but an active one in which the mentee and the mentor are dynamically involved with each other in learning.

As mentioned earlier, as students' access to HE has increased, so has the admission of non-traditional students, which has raised the issue of retention. What massification of HE has done is to highlight the need for student support programmes, including mentoring. There has been an increase in the number of students in need of mentoring because of the admission of first year undergraduate students from schooling systems that have not adequately prepared them for the demands of $\mathrm{HE}$ as well as an increase in the number of students who are regarded as being at risk of academic exclusion. To address this need, most HEIs in post-apartheid South Africa have adopted mentoring programmes that facilitate student retention (Adams 2006). Mentoring is a developmental relationship between the mentor and the mentee (Ndebele, Van Heerden \& Chabaya 2013). 
A variety of mentorship programmes exist but the focus of this article is on peer mentoring. This is a specific form of relationship between two or more students, where 'one student, only slightly more experienced, takes on a mentor role and provides guidance, instruction, and support to another less-experienced student or group of students' (Goff 2007:2). Somehow, there is reciprocity and mutual learning in peer-mentorship, as both mentees and mentors gain knowledge and develop some skills during these relationships. As an academic support programme in HE, academically successful senior students, under the guidance of academics or administrators, provide guidance and support to students who are at risk of academic exclusion as well as to those who are new to university. Such academic support is necessary to promote student success in the university. There is also evidence that 'social and academic support from peers' benefits students (Goff 2007:1) as they transition to HE.

Peer mentoring is different from ordinary mentoring because of the nature of the relationship and the power relations involved (Du Preez, Steenkamp \& Baard 2013). They observe that:

Peer mentoring within the academic context is a process whereby reciprocity and equal status abides and both mentor and mentee exchange knowledge, ideas, support and interest to the benefit of both parties. (p. 1227)

A number of studies have been conducted on mentoring programmes in South African universities. One such study was carried out in a rural-based university where Masehela et al. (2014) found that mentors were positive and committed to their role as academic support advisors. Another study on the monitoring and evaluation of peer academic support programmes in a historically disadvantaged university found that training of peer mentors was pivotal in an attempt to ensure that they possessed the required skills in mentoring their peers (Tangwe \& Rembe 2015). The study also found the importance of structured monitoring of peer mentoring activities to ensure meaningful engagements between mentors and mentees (Tangwe \& Rembe 2015). Clearly the success of these programmes depends on adequate preparation of mentors for their role (Terrion, Philion \& Leonard 2007) as well as monitoring and evaluation of the mentoring process, which suggests that effective mentoring does not happen by chance but is well structured and coordinated.

In another study, Du Preez et al. (2013) found that the programme succeeded because the mentees had entered into the mentoring arrangement because they wanted to improve their marks and to be assisted to understand difficult concepts. Ntakana (2011) concludes that in order for student academic support programmes to be meaningful, the intended outcomes should be clearly stated. Programme inputs and processes can then be directed towards achievement of the set outcomes. What this says is that such programmes work best if students are not compelled to attend but participate because they see value in it.

\section{Research methodology}

At the end of Semester 1 in 2016, mentors had a debriefing session where we asked them to reflect on their experiences of participating in this programme. This study was evaluative in nature and an 'objectives-oriented approach' was used to determine how the programme could be improved (Goff 2007:2; Robson 2002). Using an interpretivist research paradigm, we tried to understand student mentors' experiences of participating in this programme. Interpretivists hold the epistemological view that knowledge is a result of subjective experiences of key role players (Holloway \& Wheeler 2010; Neuman 2014). This enabled us to gain a holistic understanding of the views, feelings and perceptions of peer mentors regarding their role in facilitating this mentorship programme. We drew a purposive sample of 30 mentors from one campus of the university and generated qualitative data through a debriefing workshop. To answer the research question, mentors were divided into six groups of five (G1-G6) and the groups' deliberations were captured by scribes and these were presented to the plenary during discussion. Group members were free to elaborate on what the group representatives had said if they so wished. Data were analysed using the thematic content analysis technique.

\section{Ethical considerations}

This study received ethical clearance from the university where the study was conducted. No informed consent was signed but participants were informed of the study and participated willingly.

\section{Results}

During the workshop, mentors reflected on the various intervention strategies used in the mentorship programme, particularly focusing on what worked well, what did not work well and why. We have used the four pillars of the programme as organising themes. Participants' views are summarised in Table 1 and elaborations are provided under each theme.

\section{Strategy 1: Workshops}

This section presents results of the group discussions on the effectiveness of workshops as an integral component of the peer mentoring programme.

Participants confirmed that workshops were held weekly during the timetabled free period (FORUM period) where different academic skills were offered to mentees and any other students who chose to attend. The following verbatim quotations of group reports show how workshops were utilised to offer academic skills to students:

'Workshops included academic writing skills, time management, study skills, etc. The majority of mentees showed up and fully participated during the workshops.' (G1) 
TABLE 1: Participants' views on key structured intervention strategies.

\begin{tabular}{|c|c|c|}
\hline Key mentoring strategy & What worked well & What did not work well \\
\hline Workshops & $\begin{array}{l}\text { The use of free period for mentoring activities. } \\
\text { Academic skills offered to students. } \\
\text { Popularity of academic skills workshops. } \\
\text { Attendance by first year students. }\end{array}$ & $\begin{array}{l}\text { Communication through emails. } \\
\text { Senior students' reluctance to attend workshops. }\end{array}$ \\
\hline Drop-in centre & $\begin{array}{l}\text { The existence of a central place where mentees go to for assistance. } \\
\text { Its accessibility and convenience for meetings. } \\
\text { Availability of someone to assist in the drop-in centre. } \\
\text { Availability of mentors' timetables. } \\
\text { Individual learning needs addressed in one-to-one consultation. } \\
\text { Option to refer students to coordinator if need could not be addressed. }\end{array}$ & $\begin{array}{l}\text { Inability to address urgent needs. } \\
\text { Inability to attend to needs outside mentor's scope of expertise. }\end{array}$ \\
\hline Weekly themes & $\begin{array}{l}\text { Mentors given weekly themes to reinforce in group and individual meetings. } \\
\text { Weekly themes dealt with as per plan. }\end{array}$ & $\begin{array}{l}\text { Poor attendance of meetings by some mentees, especially those at } \\
\text { risk of failure. }\end{array}$ \\
\hline Food drive & $\begin{array}{l}\text { Food campaign to support hungry mentees. } \\
\text { Staff and funded students supported the drive. } \\
\text { Needy students felt cared for. }\end{array}$ & $\begin{array}{l}\text { Oversupply of some food items. } \\
\text { Midmonth to month-end the food boxes were often empty. } \\
\text { Students' fear of being stigmatised as poor. }\end{array}$ \\
\hline
\end{tabular}

'Workshops were effective because they familiarised mentees and mentors with university proceedings and taught mentors to become agents of change through time management skills, study skills and communication skill.' (G4)

The fact that group 4 thought both mentees and mentors benefited from the workshops confirmed the reciprocal nature of peer-mentorship highlighted earlier (Knippelmeyer \& Torraco 2007). These workshops took place every Thursday at the same time during a timetabled free period. All the mentors were encouraged by the regularity and enthusiasm of first year mentees' attendance. However, students regarded as at risk of academic exclusion were not as forthcoming, as captured in these excerpts:

'First year students came in their numbers to attend the workshop but some senior students who were supposed to attend always had excuses of study group meetings or other commitments.' (G5)

'In our group we also felt that first year students are the ones that showed the most commitment.' (G4)

'Students 'at risk' don't come regularly to workshops and group meetings; some are aware of what they need to do. They only come when they are desperate for help.' (G1)

The popularity of the academic skills workshops was obvious.

'They [workshops] were effective because [a] majority of them showed up or attended the meetings. The number of people attending keeps on increasing week by week.' (G1)

'A number of mentees came to attend workshops towards exam time and when they were struggling with [the] work load.' (G5)

The above statements suggest that the intended beneficiaries of the workshops were embracing them. It was also comforting to learn that when students felt under pressure they remembered that support was available through these workshops. This confirms what Du Preez et al. (2013) found that when mentees saw value in the programme (improvement of marks or understanding of concepts), they were more committed.

However, sometimes there were logistical problems that students had to find ways to deal with:

'At times it was difficult to meet mentees because of timetable clashes. We then communicated through emails but it's not like meeting and discussing face to face. Even with FORUM period some mentees attend group meetings, especially students that stay away from campus residence.' (G3)

'Some mentees will leave assignments and queries till [the] last minute, sometimes when we are not available to assist immediately.' (G3)

When there were challenges like timetable clashes, mentors found alternate ways to support their mentees. Although most mentees seemed to develop the skills taught through the programme, there were those who lagged behind in their learning and remained dependent much longer. At university level students are expected to operate independently and to selfregulate (Heirdsfield et al. 2008) but some students will take longer to reach that level and require more guidance than others.

\section{Strategy 2: Weekly themes}

These weekly themes are a follow-up of weekly workshops where mentors are required to arrange meetings with their mentees where they reinforce skills learnt in their weekly meetings. There were mixed feelings about the effectiveness of these:

'Weekly themes gave us directions on what to discuss with mentees.' (G2)

'Weekly themes were sometimes not relevant to everyone. For an example, if you don't have a problem with time management there would be no need to attend. Some mentees will come because of a particular theme.' (G1)

'Weekly themes were very effective; these themes helped mentees to stay on track, by developing study skills as well as reading and understanding questions, which is important when writing academic papers.' (G4)

A concern was also raised on the absence of some mentees from scheduled meetings that focused on the given themes:

'Poor attendance because of transport issues especially for offcampus students who are taking lift clubs.' (G3)

'Some senior 'at risk' students were sent emails to attend the mentorship programme; they did not come for group meetings and workshop but they ask for appointment for individual meetings.' (G1)

'Some of my mentees had a "catch up" lecture during FORUM period and they were unable to attend our meetings.' (G2)

'We tried so many times to send emails to make appointments with mentees. Some responded but some not. Some students just don't read emails.' (G4) 
Absence from scheduled meetings by the intended beneficiaries of the peer support programmes, as shown above, can negatively affect mentees, especially those already at risk of academic exclusion. The intention of weekly themes and meetings is to reinforce whatever skills have been taught as one period of $45 \mathrm{~min}$ is not adequate to explain or understand how one can manage their time or how to study effectively. During the rest of the week, mentees can meet their mentors where these skills are broken down into manageable steps that mentees can begin to implement.

\section{Strategy 3: Drop-in centre}

The mentors felt that one of the important things about the peer-mentorship programme was the existence of a central place where assistance to mentees could be rendered. The accessibility of the venue to both mentees and mentors was a big plus. The following comments support this view:

'The drop-in centre strategy was effective because there were always two or three mentors available, and if students needed subject-specific help they could get an appointment with a relevant mentor.' (G4)

'Some mentors preferred to spend their free periods at the dropin centre because they were able to address individual problems on the spot as we were available when students needed someone to talk to.' (G1)

'Some students gave positive feedback (about the drop-in centre). It is also a conducive environment for one to study; it is peaceful.' (G6)

The existence of a central place was regarded positively as students in need knew exactly where to go to whenever they required assistance. The accessibility of the drop-in centre also encouraged mentors to spend time there even when they were not on duty, thus increasing the availability of support to mentees:

'As mentors we followed the duty timetable at the drop-in centre; it was convenient for both mentors and mentees because you had your turn when you had a free period.' (G2)

'Drop-in centre was a huge help for mentees because there was always someone there to assist.' (G3)

The availability of a contact person at the drop-in centre ensured that mentees were always attended to. In addition, that peer mentors' timetables were available to the mentees was noted as a very good aspect of the peer mentoring programme as mentees could see who was available and when.

'Individual meetings with mentees were very productive because it is when they get comfortable to talk about their challenges and they get a chance to ask questions.' (G4)

'In my group, mentees sometimes asked to speak in their language and the atmosphere is more relaxed compared to group meetings.' (G1)

The existence of a one-on-one consultation service between mentors and mentees highlights the flexibility of this programme that mentorship happened in group as well as individual sessions. It also shows that one-on-one sessions provided a comfortable space where mentees could freely express themselves.

The mentors were also aware that they could refer their mentees to other sources of support when the support required by mentees was beyond their scope and areas of expertise:

'Some mentees will come with problems that are beyond our means; during our training we were informed about other university support sectors that we can liaise with, for example, students that needed counselling were referred to the counselling unit.' (G3)

'In my group I had a number of students who did not have funding and I took them to Student Funding office.' (G1)

It was also important to note that peer mentors were aware of their limitations in terms of either knowledge, resources or skills and made referrals to other university structures where mentees could be further supported.

Sometimes mentors felt unable to address urgent needs:

When mentees come to the drop-in centre for subject-specific assistance, and there is no mentor doing that subject, they will be shown the duty timetable when mentors doing that subject will be available. They have to come back when one of the mentors is available. (G4)

Although this could be regarded as a shortcoming of the programme, if students manage their time well, they would come when there is still enough time for the next available mentor to support them with their query.

\section{Strategy 4: Food drive}

As more first year students from previously disadvantaged backgrounds got admitted, it became evident that many had limited means to support themselves. Thus, the programme coordinator incorporated a food drive as an aspect of the peer-mentorship programme. The food drive was managed by mentors:

'In our individual meetings mentees were able to tell us about their challenges such as going to classes hungry. We designed posters to create awareness to both staff and students to donate food.' (G1)

'We had a basket in the drop-in centre where staff and students donated food parcels; it was exciting to get everyone involved.' (G4)

The cooperation of staff and students in the acquisition of food meant for needy students showed the importance of collective efforts in achievement of set goals for a good cause. It was clear from the above comments that peer mentoring activities extended beyond mere academic needs of students to other felt needs necessary for students' welfare. However, some mentors still experienced challenges, as this group related:

'Food donated was mostly canned food and other non-perishable food but some mentees needed something like bread, toothpaste and soaps.' (G3) 
'One of my mentees told me that she does not have food to eat in the morning when she is rushing to lectures because she has to cook food that she received.' (G2)

It was disturbing to learn that what is meant to support students can also be regarded as an additional source of victimisation. The following comments confirm this view:

'Some [students] shy away from receiving help or the food parcels because they are running away from stigma. But on the other hand, it has helped many students who are less fortunate since many of them don't have funding.' (G1)

'Students are afraid to receive a food parcel because they don't want to be seen as needy.' (G4)

\section{Discussion}

Because of their training and seniority, mentors were knowledgeable about the academic programme as well as resources available for student support. As such, they knew what to do and in instances where mentees brought problems that were beyond them, they knew where to refer them to. The mentors were instrumental and effective in using structured workshops to teach mentees academic skills that are deemed critical for academic success. In the process, both mentors and those mentees who committed to the mentor-mentee relationship developed social connections that contributed to the success of the whole programme. There is documented evidence that feelings of connectedness create a sense of belonging in students and contribute to retention as well as academic success (O’Brien \& Llamas 2012:7; Terrion et al. 2007:54).

The findings also show that most first year student mentees were very enthusiastic about, and committed to attending scheduled workshops. This could be because most mentors had served as orientation week mentors, and maybe this made first years regard them as knowledgeable or leaders. Alternatively, these students soon realised that the course demands were complex, that they needed the mentors' support to adjust. In working with mentors, mentees were exposed to positive behaviour modelling (Bandura 1977) as they learnt with others and co-constructed meaning (Heirdsfield et al. 2008).

The existence of one-on-one consultation services between mentor and mentees is consistent with the social learning theory around which mentoring is modelled. The mentee should be afforded the opportunity to be with the mentor and learn appropriate knowledge, skills and values (Bandura 1977). In learning from the mentor, the mentees ultimately observe and emulate the mentor and in the process internalise important study habits as well as commitment to studies. In such an arrangement there are intended and unintended outcomes, which all assist in the academic growth of the mentee. The presence of a dedicated venue (drop-in centre) facilitated this type of learning. In a study by Masehela et al. (2014) the mentoring programme was negatively affected by lack of appropriate and convenient venues.

We were concerned to learn that senior mentees (those at risk of academic exclusion) were reluctant to attend academic support workshops. This finding is inconsistent with findings in earlier studies by Tangwe and Rembe (2014), Masehela et al. (2014) as well as Du Preez et al. (2013), who found that generally student mentees were very keen to attend scheduled mentoring programmes. Probably they were keen because of the desire to learn peer mentors who offered support in a relaxed and collegial manner, which is different from the lecture room set-up (Mudzielwana \& Maphosa 2013). Maybe the programme coordinator needs to consider assigning at risk students to post-graduate mentors. There is a possibility that these mentees will find it easier to relate to post-graduate mentors than to those they regard as their peers.

The findings also show that as much as some participants realised the value of attending the support programme, there were a few challenges, including the following:

1. Means of communication between mentors and mentees. The problems of communication cannot be solved through the programme as it is each mentee's responsibility to look for information. During orientation into the peer-mentorship programme they are advised to check their emails regularly and to inform their mentors should their contact details change.

2. Stigma, which means few mentees who were at risk attended intervention programmes because others felt stigmatised and embarrassed to attend workshops. This finding is consistent with findings by Latino and Unite (2012), who reported that students displayed resentment about the way in which academic support singled out students and made them feel stigmatised.

3. Fear of collecting food parcels because of labelling. Findings suggest that some financially needy students were reluctant to receive food parcels because they did not want to be labelled as needy.

4. Timing of the workshops. Some mentees did not attend the workshops because they had other commitments, group sessions and social activities. Since attendance was not compulsory, each mentee chose what was more important to them.

\section{Summary, conclusion and recommendations for further research}

The existence of a peer support system has become a necessary academic intervention strategy to ensure both student retention and student success (Council on Higher Education 2010). Without structured intervention strategies, it would be impossible to address the retention and throughput challenges in South African universities. The issues that emerge from the mentors' experiences cannot be compressed into one discipline. For example, some of the issues that emerged from the mentors' experiences could be seen from psychological, linguistic, food and nutritional perspectives, thus conforming transdisciplinarity (Nicolescu 2008).

We conclude that the mentors' experiences in this programme were positive in that they developed important life skills. 
They learnt leadership skills like facilitating workshops, conducting follow-up sessions, initiating group meetings, providing one-on-one support and chasing after those mentees who did not see any value in the programme. Although the focus of the peer-mentorship programme is on ensuring smooth transition into university as well as the provision of academic support to those students deemed at risk of academic exclusion, the findings of this study highlight the significant role played by mentors in the successful running of such a programme. What this suggests is that mentor training is a critical component of such a programme. If mentors are to remain knowledgeable, positive and committed in their work, HEIs need to provide resources to ensure that student support programmes like this are successfully run.

Future research could solicit mentees' experiences of such programmes, especially those who seem reluctant to participate. This will assist in highlighting their mentorship needs, which will enhance the implementation of the programme and foster the academic success of all participants. Further, it would be of interest to explore lecturers' views of the value of such programmes in supporting transitioning students as well as those at risk of academic exclusion and how they think the programme could be enhanced.

\section{Acknowledgements Competing interests}

The authors declare that they have no financial or personal relationships which may have inappropriately influenced them in writing this article.

\section{Authors' contributions}

S.N. was responsible for the literature review, data collection, analysis and addressing the reviewers' comments. S.M. contributed to sample preparation and collected the data. Both authors contributed to the interpretation of results, discussed the results and contributed to the final writing of the article.

\section{References}

Adams, J.D., 2006, 'Prevailing and preferred learning practices in University Student Support Programmes', Unpublished Doctoral thesis, University of Zululand, KwaDlangezwa.
Akoojee, S. \& Nkomo, M., 2007 'Access and quality in South African higher education: The twin challenges of transformation', South African Journal of Higher Education 3, 385-399.

Altbach, P.G., 1999, 'The logic of mass higher education', Tertiary Education and Management 5(2), 107-124. https://doi.org/10.1080/13583883.1999.9966985

Bandura, A., 1977, 'Self-efficacy: Toward a unifying theory of behavioural change', Psychological Review 84(2), 191-215. https://doi.org/10.1037/0033-295X.84.2.191

Council on Higher Education (CHE), 2010, 'Access and throughput in South African higher education: Three case studies', Higher Education Monitor No. 9, March, CHE, Pretoria.

Department of Education, 1997, 'Education white paper 3: A programme for higher education transformation', Department of Education, Pretoria.

Du Preez, R., Steenkamp, L.P. \& Baard, R.S., 2013, 'An investigation into a peer module mentoring programme in Economic and Management Sciences', International Business \& Economics Research Journal 12(10), 1225-1238.

Goff, L., 2007, 'Evaluating the outcomes of a peer-mentoring program for students transitioning to postsecondary education', The Canadian Journal for the Scholarship of Teaching and Learning 2(2), 1-13.

Heirdsfield, A.M., Walker, S., Walsh, K. \& Wilss, L.A., 2008, 'Peer mentorship for first year teacher education students: The mentors' experience', Mentoring and Tutoring: Partnership in Learning 16(2), 109-124. https://doi. org/10.1080/13611260801916135

Holloway, I. \& Wheeler, S., 2010, Qualitative research in nursing and healthcare, 1st edn., Wiley-Blackwell, Chichester, West Sussex, UK.

Knippelmeyer, S.A. \& Torraco, RJ., 2007, 'Mentoring as a developmental tool for higher education', paper presented at the Academy of Human Resource Development International research conference in the Americas, Indianapolis, IN, February 28-March 4.

Latino, J. A. \& Unite, C. M., 2012, 'Providing academic support through peer education' New Directions for Higher Education 157, 31-43. https://doi.org/10.1002/ he. 20004

Masehela, L., Ndebele, C., Sikhwari, T. \& Maphosa, C., 2014, 'Mentors' reflections of a pilot mentoring programme in a South African university', Anthropologist 17(2), 367-376. https://doi.org/10.1080/09720073.2014.11891446

Mudzielwana, P.M. \& Maphosa, C., 2013, 'The influence of context in South African higher education system: A social realist critique', Journal of Sociology and Socia Anthropology 4(3), 175-181. https://doi.org/10.1080/09766634.2013.11885594

Ndebele, C., Van Heerden, J. \& Chabaya, O., 2013, 'Development and implementation of a mentoring programme at a historically disadvantaged South African university', Journal of Social Sciences 34(2), 123-133. https://doi.org/10.1080/09 718923.2013.11893124

Neuman, L.W., 2014, Social research methods: Qualitative and quantitative approaches, 7th edn., Pearson Education Limited, London.

Nicolescu, B., 2008, Transdisciplinarity: Theory and practice, Hampton Press, Cresskill, NJ.

Ntakana, K.N., 2011, 'The effectiveness of student support programmes at a tertiary institution: A case study of Walter Sisulu University', MEd dissertation, University of Zululand, Durban.

O’Brien, M. \& Llamas, M., 2012, 'Lessons learned from four years of peer mentoring in a tiered group program within education', Journal of the Australian \& New Zealand Student Services Association 40, 7-15.

Robson, C., 2002, Real world research: A resource for social scientists and practitionerresearchers, Blackwell Publishers, Oxford, UK.

Tangwe, M.N. \& Rembe, S., 2014, 'The perceptions of students on the implementation of peer academic support programmes at one university in South Africa', Mediterranean Journal of Social Sciences 5(4), 378-389. https://doi.org/10.5901/ mediterranean Journ

Tangwe, M.N. \& Rembe, S., 2015, 'Monitoring and evaluation of peer academic support programs in South African higher education institutions: A case of one university in the Eastern Cape Province', International Journal of Education Sciences 8(2), 249-260. https://doi.org/10.1080/09751122.2015.11890246

Teferra, D. \& Altbach, P.G., 2004, 'African higher education: Challenges for the 21st century', Higher Education 47, 21-50. https://doi.org/10.1023/B:HIGH.0000009822 .49980 .30

Terrion, J.L., Philion, R. \& Leonard, D., 2007, 'An evaluation of a university peermentoring training programme', International Journal of Evidence Based Coaching and Mentoring 5(1), 42-57. 